\title{
SIMULASI ANTRIAN PELAYANAN BANK DENGAN MENGGUNAKAN METODE GAMMA
}

\author{
Christian Adi Pratama Saragih ${ }^{1}$, Akim Manaor Hara pardede ${ }^{2}$, Katen Lumbanbatu ${ }^{3}$ \\ STIMIK KAPUTAMA \\ ${ }^{1,3}$ Prodi TeknikInformatika, ${ }^{2}$ Prodi SistemInformasi \\ ${ }^{1}$ christiansaragi6@gmail.com, ${ }^{2}$ akimmhp@ live.com, ${ }^{3}$ k.lumbanbatu@yahoo.com
}

\begin{abstract}
ABSTRAK
Penelitian ini membahas simulasi antrian di bank dengan menggunakan metode gamma. Tujuan penelitian ini adalah untuk merancang dan menerapkan metode gamma untuk mensimulasikan antrian layanan pelanggan bank. Dalam sistem antrian biasanya ada tiga komponen yang saling berhubungan satu sama lain kedatangan, antrian atau antrean. Melalui simulasi yang akan dilakukan dapat dilihat bahwa kinerja sistem yang diamati akan dikoreksi sehingga mendapatkan perbaikan agar benchmark untuk layanan dapat berjalan lebih baik lagi. Dalam penelitian ini peneliti menggunakan distribusi Poisson untuk kedatangan pelanggan tunggal dengan teller tunggal dan antrian tunggal mengikuti aturan FIFO. Berdasarkan hasil penelitian, ada empat server yang memadai untuk melayani, jika hanya satu server akan menghasilkan waktu tunggu rata-rata yang sangat panjang yang menyebabkan pelanggan bosan, sementara dengan dua server masih menghasilkan rata-rata lama menunggu waktu dan menyebabkan antrian, jika menggunakan tiga server jumlah waktu tunggu tidak terlalu lama dan tidak membuat antrean panjang. Untuk penelitian selanjutnya diharapkan akan dikembangkan simulasi antrian yang memiliki kedatangan atau layanan dengan distro lain dan dapat digunakan sebagai acuan dalam pengambilan keputusan guna memaksimalkan waktu layanan pelanggan atau menambah jumlah server sebagai pelayan, dan meminimalkan server jika dianggap berlebihan dalam layanan untuk meminimalkan biaya operasional.
\end{abstract}

Kata kunci: Simulasi, Antrian, Metode Gamma.

\begin{abstract}
This research discusses the simulation of queue in bank by using gamma method. The purpose of this research is to design and apply gamma method to simulate queue of customer service of bank. In the queue system there are usually three components that are interconnected to each other arrival, queuing or waiting line. Through the simulation will be done can be seen that the performance of an observed system will be corrected so as to get improvements for benchmarks for service can run better again. In this study researchers used Poisson distribution for single customer arrivals with single teller and single queue following FIFO rules. Based on the results of the study, there are four servers that are adequate to serve, if only one server will result in a very long average waiting time which causes the customer to get bored, while with two servers still result in the average long waiting time and cause queue, if using three the server the amount of waiting time is not too long and does not make long queues. For further research is expected to be developed simulation queue that has the arrival or service with other distributions and can be used as a reference in making decisions in order to maximize customer service time or increase the
\end{abstract}


number of servers as servants, and minimize the server if considered excessive in a service in order to minimize operational costs.

Keywords: Simulation, Queue, Gamma Method.

\section{PENDAHULUAN}

Antrian merupakan sebuah aktifiitas dimana pelanggan menunggu untuk memperoleh sebuah layanan. Situasi dalam menunggu juga merupakan bagian dari keadaan yang terjadi dalam rangkaian kegiatan operasional yang bersifat acak atau tidak beraturan dalam fasilitas pelayanan. Dengan mempelajari teori sistem simulasi diharapkan penyedia suatu layanan dapat meningkatkan pelayanan agar pelanggan dapat merasa nyaman dan adil atas pelayanan tersebut.

Antrian timbul disebabkan oleh kebutuhan akan layanan melebihi kemampuan (kapasitas) pelayanan atau fasilitas layanan, sehingga pengguna fasilitas yang tiba tidak bisa segera mendapat layanan disebabkan kesibukan layanan. Pada banyak hal, tambahan fasilitas pelayanan dapat diberikan untuk mengurangi antrian atau untuk mencegah timbulnya antrian. Tetapi memberikan pelayanan tambahan akan menimbulkan pengurangan keuntungan mungkin sampai di bawah tingkat yang dapat diterima. Sebaliknya, sering timbulnya antrian yang panjang akan mengakibatkan hilangnya pelanggan/nasabah.

Dalam sistem antrian biasanya terdapat tiga komponen yang saling terkait satu sama lain yaitu kedatangan, antrian atau garis tunggu. Ketiga komponen harus dipertimbangkan lebih dahulu sebelum dapat mengembangkan model matematika dari antrian yang diamati. Melalui simulasi yang akan dilakukan akan dilihat bahwa kinerja dari suatu sistem yang diamati akan di koreksi sehingga mendapatkan perbaikan untuk tolak ukur agar pelayanan dapat berjalan lebih baik lagi.

Pada peneliian sebelumnya menggunakan metode Hyperexponential sebagai metode pelayanan pada nasabah, kesimpulannya adalah jumlah server terbaik pada suatu bank studi kasus yang dibahas adalah dengaan menggunakan 3 server. Pardede, AMH. 2018)[1] .

Penelitian ini diperkuat oleh penelitian sebelumnya yang berjudul "Simulasi Sistem Antrian Kedatangan Berkelompok Dengan Pelayanan Weibull Oleh Banyak Server" (Pardede, Akim M.H, 2014, Jurnal Teknologi Informasi dan Komunikasi, ISSN : 23385839. Volume : III, Nomor : 1. 110.BBPPKI, Medan) [2] , dari hasil referensi tersebut penulis menghasilkan salah satu kesimpulan yang cukup mendekati yaitu dengan metode gamma.

Berdasarkan latar belakang di atas, maka yang menjadi rumusan permasalahan adalah :

1. Dengan menggunakan metode gamma, bagaimana cara melakukan simulasi antrian pelayanan di instansi lain yang membutuhkan?

2. Dengan menggunakan VB.NET 2010, bagaimana merancang program untuk membuat simulasi antrian pelayanan nasabah bank? 
Manfaat yang di peroleh dari hasil penelitian ini adalah :

1. Dapat membantu Bank untuk menentukan jumlah server layanan yang tepat.

2. Dapat meningkatkan pelayanan dengan baik kepada nasabah.

\section{Pengertian Simulasi}

Kata simulasi berasal dari bahasa asing (Inggris) yaitu to simulate yang berarti menirukan, sedang kata simulation yang diterjemahkan ke bahasa Indonesia dengan simulasi mempunyai makna tiruan atau upaya menirukan, yaitu menirukan suatu sistem nyata (real system) yang menjadi obyek kajian dalam rangka mencari jawaban atas persoalan sistem tersebut.

\section{Sistem Antrian}

Situasi dimana pelanggan harus menunggu untuk diberikan layanan, lama dalam pelayanan hingga selesai semua layanan, semua situasi ini merupakan bagian dari antrian selama pelanggan mulai masuk kedalam sistem antrian (Simamora, R.J., 2010)[3] .

Sistem antrian adalah merupakan keseluruhan dari proses para pelanggan atau barang yang berdatangan dan memasuki barisan antrian yang seterusnya memerlukan pelayanan sebagaimana seharusnya berlaku. Dalam mempelajari suatu sistem antrian, perlu untuk diketahui struktur sistem antrian, yaitu unit yang memerlukan pelayanan disebut pelanggan (customer) dan yang melayani disebut pelayan (server). (Pardede, 2014, h.2)[1] .

\section{Struktur Sistem Antrian}

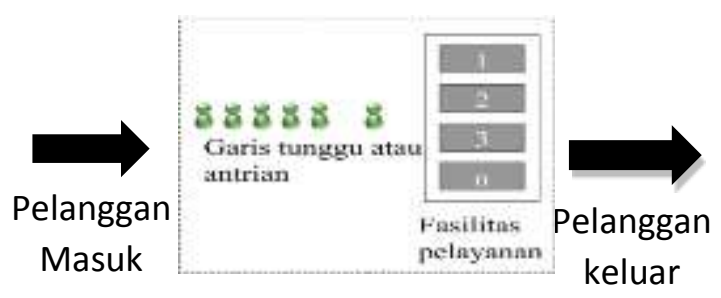

Gambar 1. Struktur Sistem Antrian

\section{KomponenAntrian}

Antrian ada 3 (tiga) komponen utamadalam teori antrian yang harus benar-benar diketahui dan dipahami (Pardede, 2013, h.5) [4] , yaitu:

a. Tingkat kedatangan

b. Tingkat pelayanan

c. Disiplin antrian

\section{FaktorSistemAntrian}

Faktor-faktor yang berpengaruh terhadap barisan antrian dan pelayanannya adalah sebagai berikut (Pardede, 2013, h.6)[4]:

1. Distribusi Kedatangan

Pada sistem antrian, distribusi kedatangan merupakan faktor penting yang berpengaruh besarterhadap kelancaran pelayanan. Distribusi kedatangan terbagi dua,yaitu :

a. Kedatangan secaraindividu (tunggal $=$ singlearrivals)

b. Kedatangan secaraberkelompok (bulkarrivals)

Kedua komponen ini harus mendapatkan perhatian yang memadai pada saat pendisainan sistem pelayanan.

2. Distribusi Waktu Pelayanan

Distribusi waktu pelayanan berkaitan dengan berapa banyak fasilitas pelayanan yang dapat disediakan. Distribusi waktu 
pelayanan terbagi menjadi dua komponen penting, yaitu :

a. Pelayanan secara individual (singleservice)

b. Pelayanan secara kelompok (bulkservice)

3. Fasilitas pelayanan

Fasilitas pelayanan berkaitan erat dengan baris antrian yang akan dibentuk. Desain fasilitas pelayanan ini dapat dibagi dalam tigabentuk,yaitu :

a. Bentuk series, dalam satu garis lurus ataupun garis melingkar.

b. Bentuk paralel,dalam beberapa garis lurus yang antara satu dengan yang lain parallel.

c. Bentuk networkstation, yang dapat didesain secara series dengan pelayanan lebih dari satu pada setiap stasiun. Bentuk ini dapat juga dilakukan secara paralel dengan stasiun yang berbeda-beda. Dengan demikian bentuk fasilitas pelayanan ini juga harus diperhitungkan dalam sistem antrian.

4. Disiplin pelayanan

Disiplin pelayanan berkaitan erat dengan urutanpelayanan bagi pelangganyang memasuki fasilitas pelayanan.

5. Ukuran dalam antrian

Besarnya antrian pelanggan yang akan memasuki fasilitas pelayanan pun perlu diperhatikan. Adadua desainyang dapat dipilih untuk menentukan besarnya antrian,yaitu :

a. Ukuran kedatangan secaratidak terbatas (infinitequeue)

b. Ukuran kedatangan secaraterbatas (finite queue)

6. Sumber pemanggilan

Dalam fasilitas pelayanan, yang berperan sebagai sumber pemanggilan dapat berupa mesin maupun manusia. Bila ada sejumlah mesin yang rusak maka sumber pemanggilan akan berkurang dantidak dapat melayani pelanggan. Jadi masalahnya adalah apakah :

a. Sumber panggilan terbatas (finite calling source)

b. Sumber panggilan takterbatas (infinite calling source)

\section{Distribusi Poison}

Suatu distribusi mengikuti poladistribusi poisson jika mengikuti aturan berikut ini (Pardede, 2013, h. 12) [4]:

a. Tidakterdapatduakejadian yang terjadibersamaan.

b. Proses kedatangan bersifat acak.

c. Rata-rata jumlah kedatangan per interval waktu sudah diketahui dari pengamatan sebelumnya.

d. Bilainterval waktu dibagi kedalam interval yang lebih kecil, maka pernyataan pernyata berikut ini harus dipenuhi:

a. Probabilitas tepat satu kedatangan adalah sangat kecil dan konstan.

b. Probabilitas dua kedatangan atau lebih selama interval waktu tersebut angkanya sangat kecil sehingga mendekati nol.

c. Jumlah kedatangan pada interval waktu tersebut tidak tergantung o ada kedatangan di interval waktu sebelum dan sesudahnya.

Berikut ini merupakan probability mass function dari distribusi poisson:

$$
P(x)=\frac{\lambda^{x}}{x !} e^{-\lambda}, x=0,1,2, \ldots ., \lambda>0
$$




\section{Distribusi Gamma}

Distribusi Gamma hanya digunakan jika jumlah kejadian yang berhasil berupa integer. Jika jumlah kejadian berhasil bukan integer, maka variabel acak Gamma tidak dapat direpresentasikan dengan menggunakan jumlah variabel acak eksponensial yang identic. Distribusi Gamma biasanya memiliki kurva berbentuk kurva normal yang menjulur positif. Berikut ini merupakan probability density function dari distribusi Gamma kedatangan dan pelayanan. Gambar $X \sim \operatorname{gamma}(\alpha, \beta)$ digunakan untuk menunjukkan bahwa variabel acak $\mathrm{X}$ memiliki distribusi gamma. Variasi gamma acak $\mathrm{X}$ dengan parameter skala positif $\alpha$ dan parameter bentuk positif $\beta$ memiliki fungsi kepadatan probabilitas.

$\mathrm{f}(\mathrm{x})=\frac{x^{\beta-1} e^{-x / \alpha}}{\alpha^{\beta} \Gamma(\beta)} \quad ; \mathrm{x}>0$.

Berikut ini formula distribusi Gamma untuk lama waktu pelayanan :

Distribusi gamma dapat digunakan untuk memodelkan waktu layanan, masa pakai benda, dan waktu perbaikan. Distribusi gamma memiliki ekor kananeksponensial. Fungsi kepadatan probabilitas dengan beberapa kombinasi parameter diilustrasikan di bawah ini.

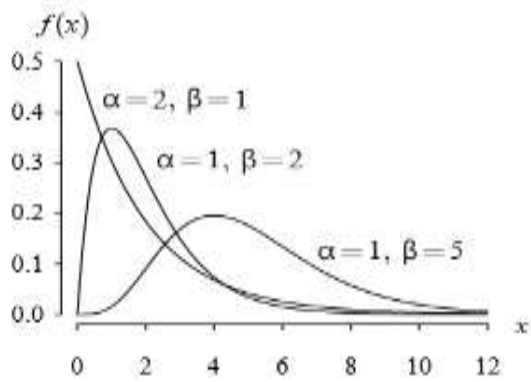

Gambar 2. Metode Gamma

\section{Bilangan Acak}

Bilangan random digunakan untuk menentukan berapa lama waktu yang digunakan. Untuk menentukan input probabilistic, dibangkitkan bilangan acak yang sesuai dengan distribusi kejadian yang akan disimulasikan.

a. Bilangan Acak Distribusi Gamma

Untuk membangkitkan suatu bilangan acak yang berdistribusi Gamma dapat diperoleh dengan :

$>>\mathrm{mu}=1: 5$;

$>\mathrm{y}=\operatorname{gampdf}(1,1, \mathrm{mu})$

$\mathrm{y}=$

$\begin{array}{lll}0.3679 & 0.3033 & 0.2388\end{array}$

0.1947

0.1637

\section{METODE PENELITIAN}

Adapun teknik pengumpulan data yang digunakan adalam penelitian ini adalah :

1. Studi Pustaka, penelitian ini dilakukan dengan cara pemahaman terhadap literature yang berupa buku - buku wajib, catatan perkuliahan yang berhubungan dengan Teori Antrian.

2. Penelitian Lapangan berupa pengamatan, yaitu peneliti melakukan berbagai pengamatan mengenai proses antrian pelayanan pada Bank Syariah Mandiri, peneliti mengamati bagaimana antrian terjadi, waktu antrian dan lama pelayanan pada antrian tersebut.

\section{Rancangan Penelitian}

Pada penelitian ini peneliti akan membahas antrian menggunakan distribusi Poisson untuk kedatangan nasabah secara tunggal dengan singleteller dan singlequeue mengikuti aturan FIFO. Nasabah yang datang lebih dulu akan dilayani sampai selesai 
kemudian teller memulai pelayanan terhadap nasabah yang datang berikutnya.

Nasabah yang datang akan dilayani oleh teller, dimana urutan pelayanan terhadap nasabah yang berada dalam satu antrian sesuai dengan waktu kedatangan. Apabila teller dalam keadaan menganggur, maka salah satu nasabah dalam antrian akan langsung di layani. Waktu antar kedatangan nasabah berdistribusi Poisson dan waktu pelayanan berdistribusi gamma.

Pada umumnya untuk membentuk model matematis dari suatu keadaan nyata sehari-hari diperlukan asumsiasumsi untuk menyederhanakan model, sehingga dapat diselesaikan dengan simulasi komputer dengan baik. Adapun Natasi-notasi yang akan digunakan adalah sebagai berikut :

$$
\begin{aligned}
& \lambda \quad \text { : Laju Kedatangan } \\
& \beta \quad \text { : Laju pelayanan } \\
& \alpha \text { : bilangan acak } \\
& \Gamma: \text { symbol gamma } \\
& \mathrm{C} \quad \text { : Teller }
\end{aligned}
$$

$\rho$ : Probabilitas teller sibuk

$\mathrm{L}_{\mathrm{s}}$ : Rata-rata nasabah dalam sistem

L: Rata-rata nasabah dalam antrian

$\mathrm{W}_{\mathrm{s}}$ : Rata-rata waktu tunggu dalam sistem

$\mathrm{W}_{\mathrm{q}}$ : Rata-rata waktu tunggu dalam antrian

Untuk performansi sistem antrian dapat dicari dengan rumus sebagai berikut :

a. Waktu tunggu nasabah dalam antrian = Waktu dimulai pelayanan - waktu kedatangan nasabah

b. Waktu tunggu nasabah dalam sistem = Waktu selesai pelayanan - waktu kedatangan nasabah

c. Rata-rata waktu tunggu dalam antrian (Wq)
$\mathrm{Wq}$

$=\underline{\sum \text { Waktu tunggu pelanggan dalam antrian }}$

Total pelanggan

d. Rata-rata waktu tunggu dalam sistem (Ws)

Ws

$=\underline{\text { Waktu tunggu pelanggan dalam sistem }}$ Total pelanggan

e. Rata-rata nasabah dalam antrian (Lq)

$\mathrm{Lq}$ ¿Waktu tunggu pelanggan dalam antrian Durasi

f. Rata-rata nasabah dalam sistem (Ls) Ls

$=\underline{\sum \text { Waktu tunggu pelanggan dalam sistem }}$ Durasi

g. Probabilitas server sibuk $(\rho)$

$$
\rho=\frac{\sum \text { Waktu pelayanan }}{\text { Banyak server }{ }^{*} \text { Durasi }}
$$

\section{HASIL DAN PEMBAHASAN Implementasi Metode Eksponensial pada Simulasi Antrian}

1. Kedatangan

Untuk membangkitkan kedatangan digunakan distribusi Poisson dengan pembangkit bilangan acak : $-\frac{1}{\lambda} \cdot \log (U)$, misalnya $\lambda=5$ dengan durasi $=1$ jam $(60$ menit).

Kedatangan 1 :

$\begin{array}{ll}\text { Acak } & =0 \\ \text { Interval waktu kedatangan } & =0 \\ \text { Waktu kedatangan } & =0\end{array}$

Kedatangan 2 :

Bangkitkan $U=U(0,1)=0.5750$

Interval waktu kedatangan $=-\frac{1}{5} \cdot \log$ $(0.5750)=0.0481$

$\mathrm{x}=$ Interval waktu kedatangan $* 3600=$ 173.16

Menit $=\mathrm{x} / 60=2,886=2$ menit

Detik $=\mathrm{x}$ mod $60=53.16$ detik

Waktu kedatangan $=0+0.0481=0.0481$ 
$\mathrm{x}=$ Waktu kedatangan $* 3600=173.16$

Menit $=\mathrm{x} / 60=2,886=2$ menit

Detik $=x$ mod $60=53.16$ detik

Untuk menit berlaku pembulatan ke bawah, sisa desimal masuk ke detik.

Demikian dengan kedatangan ke- $n$ dihitung dengan rumus yang sama.

Konter $=$ Total interval waktu kedatangan,

Jika konter $\geq$ durasi maka selesai, jika konter < durasi maka bangkitkan kedatangan berikutnya.

Tabel 1. Kedatangan

\begin{tabular}{|c|c|c|c|}
\hline $\begin{array}{c}\text { Kedatanga } \\
\mathbf{n}\end{array}$ & $\begin{array}{c}\text { Acak } \\
\text { Rand( } \\
\text { ) }\end{array}$ & $\begin{array}{c}\text { Interval } \\
\text { Waktu } \\
\text { Kedatanga } \\
\mathbf{n}\end{array}$ & $\begin{array}{c}\text { Waktu } \\
\text { kedatanga } \\
\mathbf{n}\end{array}$ \\
\hline 1 & 0 & 0 & 0 \\
\hline 2 & 0.5750 & 0.0481 & 0.0481 \\
\hline 3 & 0.0364 & 0.2878 & 0.3358 \\
\hline 4 & 0.6943 & 0.0317 & 0.3675 \\
\hline 5 & 0.4432 & 0.0707 & 0.4382 \\
\hline
\end{tabular}

Tabel di atas menunjukan bahwa hasil dari simulasi masih satuan decimal, untuk itu kita harus mengubah satuan tersebut menjadi satuan waktu, untuk itu di gunakan rumus :

Tabel 2 Kedatangan

\begin{tabular}{|c|c|c|c|}
\hline $\begin{array}{c}\text { Kedatanga } \\
\mathbf{n}\end{array}$ & $\begin{array}{c}\text { Acak } \\
\text { Rand( } \\
\text { ) }\end{array}$ & $\begin{array}{c}\text { Interval } \\
\text { Waktu } \\
\text { Kedatanga } \\
\mathbf{n}\end{array}$ & $\begin{array}{c}\text { Waktu } \\
\text { kedatanga } \\
\mathbf{n}\end{array}$ \\
\hline 1 & 0 & $00: 00$ & $00: 00$ \\
\hline 2 & 0.5750 & $02: 53$ & $02: 53$ \\
\hline 3 & 0.0364 & $17: 16$ & $20: 09$ \\
\hline 4 & 0.6943 & $01: 54$ & $22: 03$ \\
\hline 5 & 0.4432 & $04: 15$ & $26: 18$ \\
\hline
\end{tabular}

2. Pelayanan

Setelah sebelumnya mendapatkan total kedatangan, maka dilanjutkan untuk membangkitkan waktu pelayanan menggunakan distribusi Gamma, misalnya total kedatangan $=5$ dan $\beta=$ 10.
Untuk membangkitkan bilangan acak disini saya menggunakan program aplikasi matlab dengan rumus :

$$
\begin{aligned}
& >>\mathrm{mu}=1: 5 \text {; } \\
& >\mathrm{y}=\operatorname{gampdf}(1,1, \mathrm{mu}) \\
& \mathrm{y}= \\
& \begin{array}{llll}
0.3679 & 0.3033 & 0.2388 & 0.1947
\end{array}
\end{aligned}
$$

0.1637

\section{Nasabah 1 :}

Waktu mulai $=$ waktu kedatangan $=0$ $\alpha=0.3679$

Waktu layanan $=\frac{x^{\beta-1} e^{-x / \alpha}}{\alpha^{\beta} \Gamma(\beta)}=0.0813$

Selesai layanan $=0+0.0813=0.0813$

Waktu tunggu antrian $=0$

Waktu tunggu sistem $=0.0813$

Nasabah 2 :

Jika waktu kedatangan $\leq$ selesai layanan nasabah sebelumnya :

Waktu mulai $=$ selesai layanan nasabah sebelumnya

Jika waktu kedatangan > selesai layanan nasabah sebelumnya :

Waktu mulai $=$ waktu kedatangan

Waktu kedatangan $=0.0481<0.0813$,

\begin{tabular}{|c|c|c|c|c|c|}
\hline \multirow{2}{*}{$\begin{array}{c}\text { Hasil } \\
\text { simul } \\
\text { asi }\end{array}$} & $\begin{array}{l}\text { Wq } \\
\left(\sum \mathrm{Wa}\right. \\
\text { ktuTg } \\
\mathrm{u} / 5)\end{array}$ & $\begin{array}{c}\text { Ws } \\
\left(\sum \text { Waktu }\right. \\
\text { TguSys/5 } \\
\text { ) }\end{array}$ & $\begin{array}{c}\mathbf{L q} \\
\left(\sum \mathrm{Wak}\right. \\
\text { tuTgu/6 } \\
0)\end{array}$ & $\begin{array}{c}\text { Ls } \\
\left(\sum \mathrm{Wa}\right. \\
\text { ktuTg } \\
\text { uSys/ } \\
60) \\
\end{array}$ & $\rho$ \\
\hline & $\begin{array}{c}0.034 \\
0\end{array}$ & 0.0805 & 0.0028 & $\begin{array}{c}0.006 \\
7\end{array}$ & $\begin{array}{c}\text { 0. } \\
00 \\
38\end{array}$ \\
\hline
\end{tabular}
maka waktu mulai $=0.0813$

$\mathrm{x}=$ waktu mulai $* 3600=292.68$

Tabel 3. Pelayanan

Menit $=\mathrm{x} / 60=4.878=4$ menit

Detik $=\mathrm{x} \bmod 60=52.68=52$ detik

$\alpha=0.3033$

Waktu Layanan $=\frac{x^{\beta-1} e^{-x / \alpha}}{\alpha^{\beta} \Gamma(\beta)}=0.0670$

Selesai layanan $=0.0813+0.0670=$ 0.1483 
$\mathrm{x}=$ selesai layanan $* 3600=533.88$

Menit $=\mathrm{x} / 60=8.898=8$ menit

Detik $=x \bmod 60=53.88=53$ detik

Waktu tunggu antrian $=0.0813-0.0481$

$=0.0332$

$\mathrm{x}=$ Waktu tunggu antrian $* 3600=$ 119.52

Menit $=\mathrm{x} / 60=1.992=1$ menit

Detik $=x \bmod 60=59.52=59$ detik

Waktu tunggu sistem $=0.1483$

$0.0481=0.1002$

$\mathrm{x}=$ Waktu tunggu sistem $* 3600=360.72$

Menit $=\mathrm{x} / 60=6.012=6$ menit

Detik $=\mathrm{x} \bmod 60=0.72=0$ detik

Untuk menit berlaku pembulatan ke bawah, sisa desimal masuk ke detik.

Demikian dengan nasabah ke- $n$ dihitung dengan rumus yang sama.

Tabel 4. Pelayanan

\begin{tabular}{|l|l|l|l|l|l|l|l|}
\hline $\begin{array}{l}\text { Nas } \\
\text { bah }\end{array}$ & $\begin{array}{l}\text { Waktu } \\
\text { Kedat } \\
\text { ngan }\end{array}$ & $\begin{array}{l}\text { Laya } \\
\text { an }\end{array}$ & acak & $\begin{array}{l}\text { Wak1 } \\
\text { Laya } \\
\text { an }\end{array}$ & $\begin{array}{l}\text { Seless } \\
\text { Laya } \\
\text { an }\end{array}$ & $\begin{array}{l}\text { Wak } \\
\text { tung: } \\
\text { untri } \\
\text { ant } \\
\text { n }\end{array}$ & $\begin{array}{l}\text { Wak } \\
\text { ung } \\
\text { siste } \\
\text { m }\end{array}$ \\
\hline 1 & 0 & 0 & 0.367 & 0.081 & 0.081 & 0 & $\begin{array}{l}0.08 \\
3\end{array}$ \\
\hline 2 & 0.0481 & 0.081 & 0.303 & 0.067 & 0.148 & 0.033 & $\begin{array}{l}0.10 \\
2\end{array}$ \\
\hline 3 & 0.3358 & 0.335 & 0.238 & 0.044 & 0.380 & 0 & $\begin{array}{l}0.04 \\
4\end{array}$ \\
\hline 4 & 0.3675 & 0.458 & 0.194 & 0.025 & 0.484 & 0.091 & $\begin{array}{l}0.11 \\
9\end{array}$ \\
\hline 5 & 0.4382 & 0.484 & 0.163 & 0.013 & 0.498 & 0.046 & 0.06 \\
\hline
\end{tabular}

Tabel 5. Pelayanan dalam satuan waktu

\begin{tabular}{|c|c|c|c|c|c|c|c|}
\hline $\begin{array}{l}\mathbf{N} \\
\text { as } \\
\text { ab } \\
\text { ah }\end{array}$ & $\begin{array}{c}\text { Wak } \\
\text { tu } \\
\text { Ked } \\
\text { atan } \\
\text { gan } \\
\text { (mm } \\
\text { :dd) }\end{array}$ & $\begin{array}{c}\text { Mul } \\
\text { ai } \\
\text { Laya } \\
\text { nan } \\
\text { (mm } \\
\text { :dd) }\end{array}$ & acak & $\begin{array}{l}\text { Wak } \\
\text { tu } \\
\text { Laya } \\
\text { nan } \\
\text { (mm } \\
\text { :dd) }\end{array}$ & $\begin{array}{c}\text { Seles } \\
\text { ai } \\
\text { Laya } \\
\text { nan } \\
\text { (mm } \\
\text { :dd) }\end{array}$ & $\begin{array}{c}\text { Wak } \\
\text { tu } \\
\text { tung } \\
\text { gu } \\
\text { antri } \\
\text { an } \\
\text { (mm } \\
\text { :dd) }\end{array}$ & $\begin{array}{c}\text { Wak } \\
\text { tu } \\
\text { tung } \\
\text { gu } \\
\text { siste } \\
\text { m } \\
\text { (mm } \\
\text { :dd) }\end{array}$ \\
\hline 1 & $\begin{array}{c}00: \\
00\end{array}$ & $\begin{array}{c}00 \\
: 00\end{array}$ & $\begin{array}{c}0.36 \\
79\end{array}$ & $\begin{array}{c}22: \\
04\end{array}$ & $\begin{array}{c}22: \\
04\end{array}$ & $\begin{array}{c}00: \\
00\end{array}$ & $\begin{array}{c}22: \\
04\end{array}$ \\
\hline 2 & $\begin{array}{c}02: \\
53\end{array}$ & $\begin{array}{c}22: \\
04\end{array}$ & $\begin{array}{c}0.30 \\
33\end{array}$ & $\begin{array}{c}04: \\
01\end{array}$ & $\begin{array}{c}08: \\
54\end{array}$ & $\begin{array}{c}02: \\
60\end{array}$ & $\begin{array}{c}06: \\
01\end{array}$ \\
\hline
\end{tabular}

\begin{tabular}{|c|c|c|c|c|c|c|c|}
\hline \multirow{3}{*}{3} & $20:$ & $20:$ & 0.23 & $02:$ & $22:$ & $00:$ & $02:$ \\
& 09 & 09 & 88 & 40 & 49 & 00 & 40 \\
\hline \multirow{2}{*}{4} & $22:$ & $27:$ & 0.19 & $01:$ & $29:$ & $05:$ & $07:$ \\
& 03 & 31 & 47 & 33 & 04 & 28 & 01 \\
\hline \multirow{2}{*}{5} & $26:$ & $29:$ & 0.16 & $00:$ & $29:$ & $02:$ & $03:$ \\
& 18 & 04 & 37 & 50 & 54 & 33 & 36 \\
\hline
\end{tabular}

Dari kesimpulan dengan menggunakan total kedatangan $=5$ dan $\beta=10$, di dapat hasil simulasi pada table III.5 dengan kesimpulan :

$\rho=0.2324 \times 100 \%=0.38 \%$

$\mathrm{Wq}=0.0340$

$\mathrm{x}=\mathrm{Wq} * 3600=122.4$

Menit $=\mathrm{x} / 60=2.04=2$ menit

Detik $=\mathrm{x} \bmod 60=2.4=2$ detik

$\mathrm{Ws}=0.0805$

$\mathrm{x}=\mathrm{Ws} * 3600=289.8$

Menit $=\mathrm{x} / 60=4.83=4$ menit

Detik $=x \bmod 60=49.8=49$ detik

Dapat dilihat bahwa probabilitas server sibuk adalah $0.23 \%$ dengan ratarata waktu tunggu dalam antrian 0.0340 atau 2 menit 2 detik dan rata-rata waktu dalam sistem 0.0805 atau 4 menit 49 detik.

Tabel 6. Data rata-rata kedatangan

$(\lambda)$ dan pelayanan $(\beta)$

\begin{tabular}{|c|c|c|c|c|c|c|c|c|c|c|}
\hline \multirow{2}{*}{ waktu } & \multicolumn{2}{|c|}{ h1 } & \multicolumn{2}{|c|}{ h2 } & \multicolumn{2}{|c|}{ h3 } & \multicolumn{2}{|c|}{ h4 } & \multicolumn{2}{|c|}{ h5 } \\
\hline & $\lambda$ & $\beta$ & $\lambda$ & $\beta$ & $\lambda$ & $\beta$ & $\lambda$ & $\beta$ & $\lambda$ & $\beta$ \\
\hline 08.0 & & & & & & & & & & \\
\hline 0- & 1 & 9 & 7 & 7 & 7 & 6 & 4 & 2 & 7 & 4 \\
\hline $\begin{array}{c}09.0 \\
0\end{array}$ & 3 & & & & & & & & & \\
\hline 09.0 & & & & & & & & & & \\
\hline $0-$ & 1 & 8 & 1 & 1 & 4 & 6 & 9 & 0 & 1 & 9 \\
\hline 10.0 & 2 & & 2 & 2 & 4 & 0 & & & 3 & \\
\hline 0 & & & & & & & & & & \\
\hline
\end{tabular}

\section{KESIMPULAN}

Berdasarkan hasil pembahasan dan pengujian simulasi didapatkan kesimpulansebagai berikut:

Hasil simulasi Gamma, dengan parameter $\lambda=9, \beta=7$ 
1. Jika dilayani dengan 1 server maka rata-rata server sibuk (utilityserver) $252.75 \%$, rata-rata waktu tunggu (Wq) 4 jam 35 menit 18 detik, ratarata waktu tunggu dalam sistem (Ws) 4 jam 51 menit 6 detik, dan rata-rata jumlah pelanggan dalam sistem (Lq) 44.0487 rata-rata jumlah pelanggan dalam antrian (Ls) 46.5761 rata-rata waktu tunggu masih sangat lama akan menyebabkan nasabah bosan dan pergi.

2. Jika dilayani dengan 2 server maka rata-rata server sibuk (utilityserver) $200.52 \%$, rata-rata waktu tunggu (Wq) 2 jam 33 menit 10 detik, ratarata waktu tunggu dalam sistem (Ws) 2 jam 58 menit 14 detik, dan rata-rata jumlah pelanggan dalam sistem (Lq) 24.5062, rata-rata jumlah pelanggan dalam antrian (Ls) 28.5167, rata-rata server sibuk besar dan menyebabkan masih terjadinya antrian.

3. Jika dilayani dengan 3 server maka rata-rata server sibuk (utilityserver) $127.11 \%$, rata-rata waktu tunggu (Wq) 30 menit 34 detik, rata-rata waktu tunggu dalam sistem (Ws) 54 menit 24 detik, dan rata-rata jumlah pelanggan. dalam sistem (Lq) 4.8907, rata-rata jumlah pelanggan dalam antrian (Ls) 8.7041, dengan menggunakan 3 server didapatkan probabilitas server sibuk yang mendekati $50 \%$ yang artinya, jumlah waktu masih terlalu lama dan membuat antrian panjang.

4. Jika dilayani dengan 4 server maka rata-rata server sibuk (utilityserver) $47.55 \%$, rata-rata waktu tunggu (Wq) 12 detik, rata-rata waktu tunggu dalam sistem (Ws) 12 menit 5 detik, dan rata-rata jumlah pelanggan. dalam sistem (Lq) 0.0312, rata-rata jumlah pelanggan dalam antrian (Ls) 1.9331, dengan 4 server di dapatkan antrian tidak terjadi dan cukup baik sehingga tidak ada antrian.

5. Dari hasil simulasi jumlah server yang terbaik adalah 4 server.

\section{SARAN}

Simulasi yang dilakukan pada penelitian ini adalah simulasi antrian denganpola kedatangan tunggal, untuk dapat menganalisa performansi antrian. Untukpenelitian selanjutnya diharapkan dapat dikembangkan simulasi antrian yang memilikikedatangan atau pelayanan dengan distribusi yang lain dan dapat digunakan sebagaiacuan dalam mengambil keputusan agar dapat memaksimalkan waktu pelayananterhadap pelanggan atau menambah jumlah server sebagai pelayan, danmeminimumkan server jika dianggap berlebihan dalam suatu pelayanan agar dapatmemperkecil biaya operasional

\section{REFERENSI.}

[1] A. M. H. Pardede, "SIMULASI

ANTRIAN PELAYANAN

NASABAH BANK

MENGGUNAKAN METODE

HYPEREXPONENTIAL," J. Inf.

Syst. Dev., vol. 3, no. 1, pp. 33-43, 2018.

[2] A. M. H. Pardede, H.

Mawengkang, and Z. Situmorang,

"SIMULASI ANTRIAN

KEDATANGAN

BERKELOMPOK DENGAN

PELAYANAN WEIBULL OLEH

BANYAK SERVER," J. Teknol.

Inf. dan Komun., vol. 3, no. 1, pp. 
$1-10,2014$.

[3] R. J. Simamora, "Simulasi Antrian

Multiple Server Dengan Pola

Kedatangan Berkelompok," Tesis,

Program Pasca Sarjana Ilmu

Komputer, Universitas Gadjah

Mada, Yogyakarta., 2010.

[4] A. M. H. Pardede, "Simulasi Antrian Pelayanan Berkelompok

Oleh Banyak Server." (Master's

Thesis), Universitas Sumatera

Utara, Medan. 